\title{
EDUCAÇÃO AMBIENTAL NA FORMAÇÃO DOS DISCENTES
DO CURSO DE CIÊNCIAS CONTÁBEIS DA UFERSA
}

Thiara Fernanda Rodrigues Nunes ${ }^{1}$ Thaiseany de Freitas Rêgo ${ }^{2}$

Caritsa Scartaty Moreira ${ }^{3}$

\section{RESUMO}

O estudo objetiva analisar como a Educação Ambiental (EA) é abordada no curso de graduação em Ciências Contábeis, da Universidade Federal Rural do Semiárido (UFERSA) e pela própria instituição. Para tanto, procedeu-se com a análise de conteúdo de documentos institucionais, tais como: Projeto Pedagógico Institucional (PPI), Plano de Gestão de Logística Sustentável (PGLS), Plano de Desenvolvimento Institucional (PDI) e Projeto Pedagógico de Curso (PPC). Tudo isso, considerando as orientações quanto à inserção da EA na formação de nível superior, como preconiza a Lei n. ${ }^{\circ}$ 9.795/1999 e a Resolução CNE/CP n. ${ }^{\circ}$ 2/2012, que dispõem sobre a $E A$ e as diretrizes para sua implementação, respectivamente. Ao proceder com a análise dos referidos documentos, nota-se que há uma desarticulação entre eles, quando se destaca a inserção da EA no planejamento das ações desenvolvidas pela instituição junto ao corpo discente, docente e técnico. No que concerne às ações de pesquisa e extensão, promovidas pela instituição, os dados indicam que a temática é abordada de forma transversal à área Contábil e se alinham mais aos princípios e objetivos da EA, do que a organização curricular dos cursos de graduação. Quando se avalia o curso objeto de análise, nota-se que o PPC está parcialmente desalinhado com o que preceitua as normas vigentes quanto à EA, apesar de algumas disciplinas abordarem a EA como sinônima de sustentabilidade organizacional: "Auditoria ambiental e ecologia", "Contabilidade ambiental e responsabilidade social", "Direito ambiental" e "Gestão ambiental".

Palavras-Chave: Formação em Contabilidade; Educação ambiental; Meio ambiente.

\footnotetext{
1 Pós-graduanda em Auditoria, Contabilidade e Perícia contábil pela Unicesimar/ Bacharel em Ciências Contábeis pela UFERSA. E-mail: thiara.lider@hotmail.com.

2 Doutora em Administração pela PUC-PR/ Professora Adjunto III da UFERSA. E-mail: thaiseany@ ufersa.edu.br.

${ }^{3}$ Mestre em Ciências Contábeis pela UFRN e Doutoranda em Ciências Contábeis pela UFPB. E-mail: caritsa_scarlaty@hotmail.com.
} 


\title{
THE UNIVERSITY THAT LISTENS AND SHARES: EXPERIENCING INCLUSION POLICY EXPERIENCES IN LATIN AMERICA
}

\begin{abstract}
This project is born from the practical experience of inclusion policy actions designed by the Directorate for Inclusive Policies and Actions (DAIN), of the State University of Rio Grande do Norte, in Latin America and, for this study, entitled, The university I live in is a university that listens and shares: experiencing experiences of Inclusion Policies in Latin America. It proposes a diversified theme aimed at sharing and exchanging experiences, with a view to implementing an inter-university network for the creation and implementation of actions based on the promotion of respect for the principles of human diversity and the realization of rights for the culture of peace. We will use as a methodology the reflective autobiographical narratives of training based on the studies of Josso (2010) and the principle of formative learning throughout Freire's life (2005). It results in the discussion of teacher training, educational practices and trajectories, in the daily life of territories as spaces of cultural pluralities pursuing the outbreak of the (re) enchantment of the art of educational experiences, of the solidarities that push the subjects towards reciprocity, for exchanges, through I like the search for the Other, for the reconstruction of identities, for the understanding of memory as movement, function and social construction and maintenance of bonds. The involvement, sharing and training practices, in the border regions between the plural spaces of learning, in the various areas of knowledge at the international level, are the basis for the recognition of the different subjects in their diversity, capable of dialogue, of sharing bonds anchored in their places of belonging.
\end{abstract}

Keywords: Accounting training; Environmental education; Environment.

\section{INTRODUÇÃO}

A Educação Ambiental (EA) defende a ideia de que o desenvolvimento de um mundo sustentável passa pela formação e preparação dos indivíduos para interagir adequadamente com o meio ambiente (BARBIERI; SILVA, 2011). Nesse contexto, o processo de conscientização tende a direcionar ou redirecionar suas ações e relações com a natureza. Para Barbieri e Silva (2011), a EA pode ser compreendida como um caminho capaz de garantir a sustentabilidade empresarial, ambiental e social, ao mesmo tempo em que potencializa o desenvolvimento de atitudes que garantem a qualidade de vida dos indivíduos.

Quando se destaca a EA dentro das organizações, o foco tende a ser redirecionado para a sustentabilidade organizacional, ou seja, Educação para a Sustentabilidade (EpS), que se preocupa mais em maximizar o lucro, do que em defendê-lo em sua plenitude (JACOBI, 2003). Para Roos e Becker (2012), a preocupação está na formação de indivíduos aptos a solucionar conflitos que envolvam a sustentabilidade empresarial 
e a preservação ambiental. Em se tratando da formação na área Contábil, Ribeiro, Nascimento e Bellen (2010), apontam que esse tema deve ir além da transmissão de conhecimento sobre escrituração, uma vez que os profissionais da área precisam ter parâmetros adequados para o reconhecimento, mensuração e evidenciação das interações das organizações com o ambiente natural.

A promoção da EA se fundamenta na Lei n. ${ }^{\circ}$ 9.795/1999 e na Resolução CNE/CP n. ${ }^{\circ}$ 2/2012, que apontam a necessidade de sua inclusão no processo formativo do indivíduo. Jacobi (2003) reforça que esta preocupação precisa ser apresentada e desenvolvida em todos os estágios de aprendizagem do indivíduo, para promover a construção de valores, conhecimentos e habilidades voltados à preservação ambiental. Diante disso, o presente estudo investiga sobre "Como a Educação ambiental é abordada no curso de graduação em Ciências contábeis, da Universidade Federal Rural do Semiárido (UFERSA), e pela própria instituição?"

Ante ao exposto, o estudo objetiva analisar como a Educação Ambiental é abordada no curso de graduação em Ciências Contábeis, da UFERSA, e pela própria instituição. Para tanto, tem-se como objetivos específicos: constatar o que está previsto no Projeto Pedagógico Institucional (PPI), Plano de Gestão de Logística Sustentável (PGLS) e o Plano de Desenvolvimento Institucional (PDI) e Projeto Pedagógico de Curso (PPC), quanto à EA. Ademais, cumpre verificar se a proposta formativa da instituição e do curso atendem às diretrizes previstas na Resolução CNE/CP n. ${ }^{\circ}$ 2/2012.

O presente estudo fundamenta-se na lógica abordada por Barbieri (2004), Calixto (2006), Tauchen e Brandli (2006), Teixeira e Teixeira (2006), Santos (2007), Machado e Casa Nova (2008), Galvão e Tenório (2009), Gonçalves-Dias et al. (2009), Ribeiro, Nascimento e Bellen (2010), Luiz et al. (2013), Vieira e Echeverria (2013), Brandalise et al. (2014), Munaretto e Busanello (2014), Pase et al. (2014), Silva et al. (2014) e Petarrnella, Silveira e Machado (2016), quanto à inserção da EA, mas considera o curso de Ciências Contábeis da UFERSA como objeto de análise. Também destaca que a EA é essencial para o processo formativo dos indivíduos que atuam na área de negócios e reconhece que a eficiência no uso dos recursos ambientais só é possível quando se conhece as interações da organização com o meio (RIBEIRO; NASCIMENTO; BELLEN, 2010). Nesse contexto, destaca-se que a Lei n. ${ }^{\circ}$ 9.795/1999 e a Resolução CNE/CP n. ${ }^{\circ}$ 2/2012, apontam a EA como um fator essencial para a formação do indivíduo e o estabelecimento de relações saudáveis com o meio ambiente.

Em termos práticos, o estudo permite avaliar como o curso insere a EA no processo formativo dos discentes, criando um clima de conscientização e responsabilidade com o meio ambiente. Ademais, destaca como as normas que afetam o processo formativo é compreendida e implementada pela instituição e pelo curso. A análise cuidadosa do PPI, PGLS, PDI e PPC, também permite identificar qual o nível de amadurecimento da instituição e do curso ao incluir a questão ambiental no processo formativo.

\section{FORMAÇÃO EM CONTABILIDADE}

Schmidt e Santos (2000) destacam que as práticas contábeis se manifestaram, de forma rudimentar, antes mesmo de o homem desenvolver a civilidade ou conhecer os 
números, sendo esse conhecimento resultado da necessidade de inventariar. Quando se trata do Ensino comercial da Contabilidade no Brasil, reportar-se ao século XIX, com a vinda da Família Real Portuguesa, em 1808 (PELEIAS, 2006). Paralelamente às mudanças ocorridas no processo formativo da Contabilidade, foram promulgadas normativas direcionadas às atividades exercidas pelos profissionais da área Contábil, em especial a Lei n. ${ }^{\circ} 4.320 / 1964$, Lei n. ${ }^{\circ} 6.404 / 1976$, Lei $n .^{\circ} 6.385 / 1976$ e alterações posteriores (BUGARIM; OLIVEIRA, 2014).

Para Peleias (2006), os cursos de graduação devem acompanhar as mudanças ocorridas no ambiente profissional, de modo a formar indivíduos efetivamente preparados para a atuação e com todas as habilidades e competências necessárias para a resolução de situações-problema. Para Ott e Pires (2010), a construção de uma matriz curricular, capaz de direcionar a formação de um perfil profissional adequado, deve reunir conteúdos diversos, que garantam o desenvolvimento de habilidades e competências compatíveis com a atuação, seja ela de Contador, Auditor, Perito, Consultor, dentre outras.

Quando se destaca o perfil desejado e o atendimento das propostas curriculares, Pinheiro et al. (2015) apontam que as instituições e os docentes têm dificuldade em atendê-los em sua plenitude, em razão das limitações de espaço físico e recursos disponíveis, para promover uma formação que atenda às demandas regionais e globais. Nesse contexto, Machado e Casa Nova (2008) comentam que o atendimento de pelo menos um dos perfis, requer o uso de ferramentas capazes de aproximar o discente em formação, do campo de atuação do Contador. Isso, porque, a realização de atividades que promovam a prática profissional, é essencial para o desenvolvimento das habilidades e competências requeridas à atuação profissional, o que se reflete no desempenho da instituição no Exame de Suficiência do Conselho Federal de Contabilidade (CFC) e no Exame Nacional de Desempenho dos Estudantes (ENADE) (SILVA; RÊGO, 2014; SILVA; MIRANDA; PEREIRA, 2017).

Em se tratando da promoção da prática e do alinhamento entre o que se discute em sala de aula, as demandas do ambiente de atuação do Contador, a Resolução CNE/CSE n. ${ }^{\circ}$ 10/2014 e a Proposta da Fundação Brasileira de Contabilidade (FBC), apresentada por Carneiro (2017) destaca o "Estágio curricular supervisionado" como um mecanismo capaz de aproximar esses ambientes. Dentre as formas implementadas pelas instituições, para garantir esse tipo de formação, tem-se observado o estágio curricular obrigatório e não obrigatório, além da inserção de componentes curriculares que promovem a prática contábil, com o uso de laboratórios e sistemas profissionais, para o registro de eventos e emissão de relatórios (PINHEIRO et al., 2014). Logo, as instituições podem definir o perfil que desejam formar, com base nas propostas curriculares existentes e para se alinhar às demandas do ambiente, a implementação de estágios e disciplinas de prática são essenciais.

As propostas curriculares do MEC, dispostas na Resolução CNE/CSE n. ${ }^{\circ}$ 10/2014, e da ONU, não destacam a EA e a relação com o meio ambiente, como pontos prioritários no estudo das Ciências contábeis. No entanto, a proposta emitida pela FBC denota certa preocupação com as relações com o ambiente natural, ao tratar sobre a responsabilidade socioambiental como um critério a ser considerado na atividade de gestão (CARNEIRO, 2017). Para ela, essa questão precisa ser levantada em razão de 
demonstrar a relação da organização com o ambiente natural e destacar as interações com o meio ambiente como uma oportunidade de negócio. De forma complementar, Calixto (2006) destaca que é por meio do ensino teórico e prático da $E A$, que os profissionais da área Contábil têm condições de incluir a variável ambiental em suas interações com as organizações.

\subsection{EDUCAÇÃO AMBIENTAL (EA)}

A Lei n. ${ }^{\circ} 9.795 / 1999$ define a EA como um processo no qual os indivíduos são preparados para construir saberes e atitudes que estão direcionados para a sustentabilidade e a qualidade de vida da coletividade. Para Barbieri e Silva (2011), a EA está associada diretamente à promoção de práticas vinculadas à gestão e ao desenvolvimento sustentável das organizações. Roos e Becker (2012) tratam a EA como uma metodologia fundamentada na capacidade do indivíduo em aprender e realizar ações que promovam a sustentabilidade e conscientização sobre as suas relações com o ambiente natural.

Souza, Rêgo e Giesta-Cabral (2017) comentam que quando se trata das discussões a respeito da EA, o uso do termo Educação para a Sustentabilidade (EpS) deve ser deixado de lado, por adotar uma perspectiva distinta. Isso, porque, a EA direciona-se às relações do indivíduo com a natureza, ao passo em que a EpS se volta à questão capitalista, que apregoa o desenvolvimento sustentável, como destaca a Organização das Nações Unidas para a Educação, a Ciências e a Cultura (UNESCO, 2017). Martins e Sanches (2012) também seguem essa lógica, ao reconhecer que a EpS proporciona conhecimentos e valores sociais direcionados à conservação do meio ambiente.

Ante ao exposto, destaca-se que a EA e a EpS centram-se na transmissão de conhecimentos e na mudança de comportamento do indivíduo ao interagir com o ambiente natural. Nesse contexto, a Lei n. ${ }^{\circ}$ 9.795/1999 e a Resolução CNE/CP n. ${ }^{\circ}$ $2 / 2016$, focam mais na troca de experiências e na qualidade de vida do indivíduo, do que no desenvolvimento sustentável e lucrativo das organizações, abordado pela UNESCO (2017). Isso mostra que embora haja um conflito sobre o termo ideal, ambos têm como ponto comum, a necessidade de se desenvolver um processo educativo e interdisciplinar, em que o indivíduo seja o agente transformador e garantidor da sustentabilidade.

Ao avaliar o que se entende por EA e EpS, destaca-se que é mais simples saber o que de fato não representa a EA, haja vista que criar projetos ambientais precários e que desconsiderar o contexto local é um desperdício (PALMA, 2005). Nesse contexto, a Lei n. ${ }^{\circ}$ 9.795/1999 destaca que a promoção da EA deve se iniciar no ambiente escolar, ao mesmo tempo em que vai se integrando às atividades desenvolvidas na sociedade. Logo, a EA deve permitir o desenvolvimento ações capazes de promover a conservação, recuperação e progresso do meio ambiente, vinculando ética, educação, trabalho e práticas sociais, para formar indivíduos ambientalmente responsáveis (PALMA; ALVES; SILVA, 2013).

A EA é um tema transversal, como assume Barbiere (2004), e não pode se limitar a uma disciplina pontual, mas deve ser tratada direta ou indiretamente nas disciplinas 
oferecidas em todas as esferas do ensino, ou seja, do Ensino fundamental ao Ensino Superior. No entanto, cabe respeitar as limitações próprias de cada fase de aprendizado, para que o processo de EA possa de fato ser promovido e propiciar o desenvolvimento de ações pautadas no respeito ao meio ambiente. Segundo Pase et al. (2014), ela precisa ser implementada em todos os campos e a universidade exerce um papel importante nesse contexto, por ser voltada à formação de profissionais que vão atuar, direta ou indiretamente, no ambiente.

Palma (2005) aponta que a EA pode permitir a construção de projetos beminformados sobre o meio e as necessidades da sociedade ou organizações. Isso, porque, ao ser implementada no processo de aprendizado, ela tende a promover a consciência ambiental e garantir as condições mínimas para a sustentabilidade da natureza e das empresas. Apesar disso, Gonçalves-Dias (2009) destaca que a EA só se torna eficiente, quando reconhece a necessidade de trabalhar com o processo de desconstrução de ações insustentáveis e reeducação, ou seja, permitir que maus hábitos sejam abandonados.

No Ensino Superior, Wachholz (2017) revela que enquanto a EA não for direcionada para a formação de docentes, discentes e funcionários, as melhorias e progressos de suas relações com o meio se tornam lentas e limitadas. Logo, compreende-se que a EA se configura como uma forma de impetrar a sustentabilidade, uma vez que garante o desenvolvimento e a produtividade (ROOS; BECKER, 2012). Nesse contexto, Roos e Becker (2012) e Palma, Alves e Silva (2013) comentam que é por meio da EA que se garante a EpS e os indivíduos conseguem, de fato, desenvolver uma consistência sustentável, capaz de modificar suas ações e melhorar sua relação com o ambiente natural.

\subsection{ESTUDOS ANTERIORES}

As discussões sobre a EA no processo formativo dos discentes que optam pela área de negócios, como Administração e Ciências contábeis, seguem abordagens diversas, como apresentado no Quadro 1. Segundo Kopeginski e Sakamoto (2010), a inserção da EA na formação dos cidadãos devem permitir o estabelecimento de relações saudáveis com o ambiente natural. Para Munaretto e Busanello (2014), essa postura é essencial à formação profissional e desenvolvimento de uma cultura ou consciência sustentável.

\section{Quadro 1 - Estudos sobre a área ambiental nos cursos de Administração e Ciências contábeis}

\begin{tabular}{|c|l|l|}
\hline Autores & \multicolumn{1}{|c|}{ Objetivo } & \multicolumn{1}{c|}{ Principais achados } \\
\hline \multirow{3}{*}{ Barbieri (2004) } & $\begin{array}{l}\text { Tratar de questões problemáticas } \\
\text { relacionadas com a implementação da } \\
\text { educação ambiental (EA) em cursos de } \\
\text { graduação em administração, conforme } \\
\text { estabelece a legislação brasileira. }\end{array}$ & $\begin{array}{l}\text { Os ciclos de palestras são insuficientes } \\
\text { quando se trata da EA, quando } \\
\text { desarticuladas com os conteúdos das } \\
\text { disciplinas. }\end{array}$ \\
\hline
\end{tabular}




\begin{tabular}{|c|c|c|}
\hline Calixto (2006) & $\begin{array}{l}\text { Verificar o grau de inserção da disciplina } \\
\text { contabilidade ambiental na matriz } \\
\text { curricular dos cursos de graduação } \\
\text { em Ciências Contábeis oferecidos por } \\
\text { universidades brasileiras, a importância } \\
\text { desta disciplina na visão dos } \\
\text { coordenadores e possíveis dificuldades } \\
\text { para a sua inclusão nos respectivos } \\
\text { cursos. }\end{array}$ & $\begin{array}{l}\text { Apesar de a Contabilidade ambiental } \\
\text { ser considerada importante no } \\
\text { processo formativo dos discentes, } \\
\text { nem sempre as IES as incluem entre } \\
\text { os conteúdos ministrados nos cursos, } \\
\text { em razão de problemas estruturais, } \\
\text { culturais e sociais que priorizam temas } \\
\text { de cunho mais técnico. }\end{array}$ \\
\hline $\begin{array}{c}\text { Tauchen e } \\
\text { Brandli (2006) }\end{array}$ & $\begin{array}{l}\text { Propor uma sistematização de } \\
\text { procedimentos, culminando num } \\
\text { modelo para a implantação de um } \\
\text { SGA, adaptado às IES que iniciarão } \\
\text { a implantação de um campus } \\
\text { universitário, permitindo a essas } \\
\text { instituições controlarem os impactos } \\
\text { ambientais e se adequarem à } \\
\text { legislação, ainda no momento da } \\
\text { concepção da sua infraestrutura. }\end{array}$ & $\begin{array}{l}\text { Nota-se que há uma economia com } \\
\text { a inserção de Sistemas de Gestão } \\
\text { Ambiental (SGA), que impactam na } \\
\text { produtividade e redução no consumo } \\
\text { de insumos, como: energia, água e } \\
\text { materiais de expediente. }\end{array}$ \\
\hline $\begin{array}{c}\text { Teixeira e } \\
\text { Teixeira (2006) }\end{array}$ & $\begin{array}{l}\text { Desenvolver estudos e pesquisas que } \\
\text { possam desembocar num plano de } \\
\text { inserção da Educação Ambiental no } \\
\text { Ensino de Administração. }\end{array}$ & $\begin{array}{l}\text { Os cursos de graduação em } \\
\text { Administração podem incluir a } \\
\text { disciplina de EA em sua proposta } \\
\text { formativa, desde que se mantenha } \\
\text { atenta às mudanças do ambiente, e que } \\
\text { priorize a responsabilidade ambiental e } \\
\text { o desenvolvimento sustentável. }\end{array}$ \\
\hline Santos (2007) & $\begin{array}{l}\text { Avaliar a vantagem competitiva } \\
\text { proporcionada pela educação } \\
\text { ambiental, utilizando o método } \\
\text { dedutivo, concluindo pela procedência } \\
\text { da hipótese heurística. }\end{array}$ & $\begin{array}{l}\text { A educação ambiental não se restringe } \\
\text { aos ambientes escolares, mas deve se } \\
\text { destacar em todas as organizações, de } \\
\text { modo a ser convertida em benefício a } \\
\text { competitividade. }\end{array}$ \\
\hline $\begin{array}{c}\text { Galvão e } \\
\text { Tenório (2009) }\end{array}$ & $\begin{array}{l}\text { Verificar o grau de inclusão da disciplina } \\
\text { contabilidade ambiental na matriz } \\
\text { curricular dos cursos de graduação } \\
\text { em Ciências Contábeis partindo de um } \\
\text { estudo bibliográfico sobre a mesma } \\
\text { diante as empresas e à sociedade, } \\
\text { a importância desta disciplina na } \\
\text { visão dos coordenadores dos cursos } \\
\text { de Ciências Contábeis e possíveis } \\
\text { dificuldades para a sua agregação nos } \\
\text { respectivos cursos. }\end{array}$ & $\begin{array}{l}\text { Contabilidade ambiental desperta } \\
\text { a curiosidades dos discentes, mas } \\
\text { esbarra na multidisciplinaridade, o que } \\
\text { requer a participação de indivíduos } \\
\text { com formações diversas, para permitir } \\
\text { reconhecer, mensurar e evidenciar } \\
\text { informações que expliquem a relação } \\
\text { da empresa com o meio ambiente. }\end{array}$ \\
\hline
\end{tabular}




\begin{tabular}{|c|c|c|}
\hline $\begin{array}{l}\text { Gonçalves-Dias } \\
\text { et al. (2009) }\end{array}$ & $\begin{array}{l}\text { Caracterizar a dimensão ambiental } \\
\text { do comportamento de futuros } \\
\text { administradores e explorar condições, } \\
\text { desafios e perspectivas para a } \\
\text { ampliação da formação socioambiental } \\
\text { nos projetos pedagógicos da escola de } \\
\text { gestão analisada. }\end{array}$ & $\begin{array}{l}\text { A consciência ambiental dos discentes } \\
\text { da área de Administração requer } \\
\text { uma revisão das políticas didático- } \\
\text { pedagógicas do curso, de modo a } \\
\text { prepará-lo para atuar em um ambiente } \\
\text { focado na sustentabilidade. }\end{array}$ \\
\hline $\begin{array}{c}\text { Ribeiro, } \\
\text { Nascimento e } \\
\text { Bellen (2010) }\end{array}$ & $\begin{array}{l}\text { Verificar a percepção dos } \\
\text { coordenadores dos cursos de Ciências } \\
\text { contábeis quanto à inclusão e à forma } \\
\text { de abordagem do ensino da temática } \\
\text { ambiental no processo de formação } \\
\text { dos graduandos dos cursos de Ciências } \\
\text { contábeis nas instituições de ensino } \\
\text { superior públicas brasileiras. }\end{array}$ & $\begin{array}{l}\text { A temática ambiental é reconhecida de } \\
\text { forma diferente pelos coordenadores } \\
\text { de curso da área Contábil. Isso, } \\
\text { porque, a depender da região e } \\
\text { nível de desenvolvimento dela, a } \\
\text { sua implementação prática pode ser } \\
\text { essencial para o sucesso do negócio, } \\
\text { seja quanto à sustentabilidade ou } \\
\text { relacionado à eficiência no uso de } \\
\text { recursos. }\end{array}$ \\
\hline Luiz et al. (2013) & $\begin{array}{l}\text { Analisar a aplicação da Agenda } \\
\text { Ambiental na Administração Pública } \\
\text { (A3P) e da legislação ambiental nas } \\
\text { atividades socioambientais praticadas } \\
\text { por um Instituto Federal de Educação. }\end{array}$ & $\begin{array}{l}\text { Nota-se que existe pouca orientação } \\
\text { e incentivos quanto à utilização } \\
\text { racional dos recursos naturais e bens } \\
\text { públicos, principalmente quando há } \\
\text { uma aderência parcial às normas e } \\
\text { orientações vigentes. }\end{array}$ \\
\hline $\begin{array}{c}\text { Vieira e } \\
\text { Echeverria } \\
(2013)\end{array}$ & $\begin{array}{l}\text { Discutiro Programa de Gestão Integrada } \\
\text { de Resíduos Sólidos (PGIRS), a partir } \\
\text { de uma experiência em Quirinópolis } \\
\text { (Goiás) e do acompanhamento da } \\
\text { Caixa Econômica Federal, propondo } \\
\text { a educação ambiental como estratégia } \\
\text { para ampliar a obtenção de resultados. }\end{array}$ & $\begin{array}{l}\text { A inserção de um projeto de EA, } \\
\text { voltado para a solução de problemas } \\
\text { em obras físicas, reflete na efetividade } \\
\text { dos resultados alcançados e para a } \\
\text { sustentabilidade socioambiental do } \\
\text { programa. }\end{array}$ \\
\hline $\begin{array}{l}\text { Brandalise et al. } \\
(2014)\end{array}$ & $\begin{array}{l}\text { Investigar se a incorporação de uma } \\
\text { disciplina relacionada à educação } \\
\text { ambiental nos cursos de graduação } \\
\text { contribui para a formação da } \\
\text { consciência e do consumo ambiental } \\
\text { dos universitários, atendendo às } \\
\text { Diretrizes Curriculares Nacionais para } \\
\text { a Educação Ambiental. }\end{array}$ & $\begin{array}{l}\text { A disciplina de Gestão Ambiental pode } \\
\text { levar os estudantes a colaborar com } \\
\text { o ambiente natural, por meio de suas } \\
\text { interações com o meio. }\end{array}$ \\
\hline $\begin{array}{l}\text { Munaretto } \\
\text { e Busanello } \\
(2014)\end{array}$ & $\begin{array}{l}\text { Verificar como as práticas de } \\
\text { gestão ambiental são incorporadas } \\
\text { e desenvolvidas nos projetos } \\
\text { pedagógicos dos cursos de graduação } \\
\text { do Centro de Educação Superior Norte } \\
\text { do Rio Grande do Sul (CESNORS), da } \\
\text { Universidade Federal de Santa Maria } \\
\text { (UFSM). }\end{array}$ & $\begin{array}{l}\text { Os PPCs dos cursos do CESNORS não } \\
\text { exibem objetos ou itens específicos que } \\
\text { articulem a educação ambiental, como } \\
\text { previsto nas informações institucionais, } \\
\text { o que implica na desarticulação dos } \\
\text { princípios e planos da IES com os } \\
\text { PPCs dos cursos. }\end{array}$ \\
\hline
\end{tabular}




\begin{tabular}{|c|c|c|}
\hline $\begin{array}{l}\text { Pase et al. } \\
\text { (2014) }\end{array}$ & $\begin{array}{l}\text { Analisar a percepção dos acadêmicos } \\
\text { do Curso de Administração em duas } \\
\text { Instituições de Ensino Superior de } \\
\text { Santa Maria - RS no que tange ao } \\
\text { papel do indivíduo e da universidade } \\
\text { no desenvolvimento de ações voltadas } \\
\text { à educação ambiental. }\end{array}$ & $\begin{array}{l}\text { Os estudantes não percebem o } \\
\text { seu papel na causa ambiental e } \\
\text { desconhecem as ações que são } \\
\text { promovidas em favor do ambiente } \\
\text { natural. }\end{array}$ \\
\hline $\begin{array}{l}\text { Silva et al. } \\
\quad(2015)\end{array}$ & $\begin{array}{l}\text { Examinar a relação entre os } \\
\text { comportamentos ambientalmente } \\
\text { responsáveis e a percepção de } \\
\text { educação ambiental de alunos e } \\
\text { servidores de uma instituição pública } \\
\text { federal de ensino, por meio de um } \\
\text { questionário eletrônico aplicado aos } \\
\text { alunos e servidores da instituição. }\end{array}$ & $\begin{array}{l}\text { O cuidado com a educação e gestão } \\
\text { ambiental, fundamenta-se em } \\
\text { questões como gestão de resíduos, } \\
\text { licitações sustentáveis, qualidade de } \\
\text { vida no trabalho, sensibilização dos } \\
\text { alunos, capacitação dos servidores e } \\
\text { uso racional dos recursos. }\end{array}$ \\
\hline $\begin{array}{c}\text { Petarnella, } \\
\text { Silveira e } \\
\text { Machado (2017) }\end{array}$ & $\begin{array}{l}\text { Revisar e refletir sobre a Educação } \\
\text { Ambiental (EA) e o Ensino de } \\
\text { Sustentabilidade, no campo da } \\
\text { Administração. }\end{array}$ & $\begin{array}{l}\text { AEA nos Programas de Pós-graduação } \\
\text { em Administração necessita, ainda, } \\
\text { de táticas peculiares para o efetivo } \\
\text { alinhamento da origem da informação } \\
\text { ao imperativo social. }\end{array}$ \\
\hline
\end{tabular}

Fonte: Dados da pesquisa.

Os estudos que envolvem a Educação Ambiental (EA) e o ensino em Administração, destacam a necessidade de uma capacitação focada na formação de indivíduos aptos a terem comportamentos e hábitos de consumo sustentáveis (BARBIERE, 2004). Nesse contexto, Teixeira e Teixeira (2006) enfatizam que a junção desses temas capacita os profissionais a terem senso crítico, além de estimular a autonomia, criatividade e capacidade de transformar o ambiente natural. Segundo Santos (2007) e Pereira (2013), a inserção da EA nos cursos de graduação despertam a consciência e o aprimoramento da gestão das organizações, diante dos problemas que comprometem o ambiente natural e a sustentabilidade.

A inserção da EA nos cursos de graduação em Ciências Contábeis envolve mudanças no modo como os discentes pensam ou questionam o crescimento econômico (GALVÃO; TENÓRIO, 2009). Para Ribeiro, Nascimento, Bellen (2010), a discussão da EA nesse ambiente de ensino deve ir além da difusão do conhecimento e englobar a conscientização do indivíduo quanto à importância de se conhecer e compreender como o meio ambiente e as organizações interagem. Nessa perspectiva, Brandalise et al. (2014) e Munaretto e Busanello (2014), afirmam que a EA é fundamental para ajudar aos discentes a entender como funciona o processo de reconhecimento, mensuração, registro e evidenciação de eventos contábeis comprometidos com a atividade ambiental.

\section{PROCEDIMENTOS METODOLÓGICOS}

O presente trabalho se enquadra quanto ao método, como dedutivo, em razão da análise sobre como a EAé abordada no curso de graduação em Ciências contábeis, da 
UFERSA a temática "Educação ambiental". Segundo Gil (2008), esse tipo de método permite chegar a conclusões formais e fundamentadas na lógica. No que concerne à abordagem, esse é um estudo empírico, uma vez que se utiliza da Lei n. ${ }^{\circ}$ 9.795/1999 e da Resolução CNE/CP n. ${ }^{\circ}$ 2/2012 para analisar como a EA vem sendo discutida e trabalhada tanto no âmbito da instituição, quanto no curso sob análise. Para Gil (2008), esse método envolve a prática como componente principal, uma vez que se vale do que está posto e é vivenciado no dia a dia, para a análise de dados.

Quanto aos objetivos, faz-se uso dos preceitos da pesquisa exploratória e descritiva, em razão de se valer da análise cuidadosa do PPI, PGLS, PDI, da UFERSA, e PPC, do curso de Ciências contábeis. Os estudos exploratórios objetivam analisar, em profundidade, uma determinada área do conhecimento ainda pouco explorada, como ocorre em relação à abordagem na EA na formação dos profissionais da área Contábil (BEUREN et al., 2013). Já as pesquisas descritivas focam na caracterização e sumarização de um determinado objeto de estudo, com vias a avaliar pontos de ação ou predição.

No que tange aos procedimentos, o estudo adota a análise documental e estudo de caso, em função do mapeamento da instituição e do curso, quanto a implementação da EA. Salienta-se que a pesquisa documental se vale da análise de documentos que carecem de um olhar científico para análise (MARTINS; THEÓPHILO, 2007). $O$ estudo de caso é apropriado quando se deseja conhecer, em profundidade, um determinado fato, com vias a mapeá-lo, triangulá-lo e compará-lo com as normas vigentes (BEUREN et al., 2013).

Em relação à abordagem do problema, o estudo se enquadra como do tipo qualitativo, em razão da necessidade de leitura atenta e análise de conteúdo do PPI, PGLS, PDI, da UFERSA, e PPC. Segundo Martins e Theóphilo (2007), a pesquisa qualitativa considera a análise minuciosa de documentos ou falas, e sobre as quais cabe interpretar os fenômenos. Nesse contexto, como destaca Bardin (2011), a pesquisa faz uso da análise de conteúdo de documentos já divulgados pela instituição, com vias a subsidiar a apreciação crítica da matéria abordada em cada um deles sobre a questão ambiental.

A pesquisa considera o uso de dados secundários e o recorte transversal, em razão de obter documentos extraídos do portal da UFERSA, em um único momento do tempo. Os dados secundários observam o uso de informações já publicadas anteriormente e que ainda não receberam nenhum tratamento científico (BEUREN et al., 2013), como ocorre com os documentos sob análise. Já o recorte transversal considera a coleta de dados em um único momento do tempo (HERNÁNDEZSAMPIERI; FERNÁNDEZ-COLLADO; LUCIO, 2006).

A presente pesquisa adota o estudo de caso como procedimento, destaca-que a adoção da UFERSA e do curso de Ciências contábeis, como objetos de estudo, em meio ao total de 53 (cinquenta e três) IES que oferecem o curso, no Estado do Rio Grande do Norte, ocorre em razão da disponibilidade de informações e por esse estudo ser um ensaio. Isso, porque, a ideia de averiguar a aderência às normas são essenciais não só para garantir uma formação adequada e atual para o indivíduo, mas para concebê-los como cidadãos. 
A adoção do estudo de caso, segundo Yin (2015), é imprescindível quando se deseja conhecer a fundo uma realidade que está sob investigação, o que requer a triangulação de dados. Nesse contexto, considera o uso de um método fundamentado tanto na compreensão do que está disponível para coleta, como na análise sistemática dos dados, a fim de garantir uma avaliação lógica do objeto sob análise. A ideia de triangulação, observa tanto a proposição institucional sobre o tratamento da questão ambiental, como os aspectos designados na norma vigente e assumidos pelo curso sob análise, quanto ao perfil formativo e adoção de princípios ou objetivos direcionados à promoção da EA.

No que concerne à análise de conteúdo dos documentos coletados, Bardin (2011) comenta que essa representa uma forma diferenciada de se avaliar uma matéria sob estudo. Isso, porque, se vale da associação entre o que prevê a norma e o que se observa como ação efetiva na instituição ou no curso sob análise. Sendo assim, permite avaliar o material sem manipular as mensagens apresentadas, mas identificando e elucidando pontos que podem indicar o desenvolvimento efetivo de ações voltadas para a EA, tanto na UFERSA, como no curso de Ciências contábeis da instituição.

Com relação à coleta de dados, fez-se uso de um checklist, que de acordo com Beuren et al. (2013), considera o uso de uma listagem de dados possíveis de serem publicados e sobre o qual se faz uso de uma variável dummy para preenchimento. Isso foi construído com base no conteúdo da Resolução CNE/CP n. ${ }^{\circ}$ 02/2012, que considera tanto os aspectos apontados na Lei $n .{ }^{\circ}$ 9.795/1999, como a Proposta Nacional de EA. A variável dummy adotada no estudo considera a atribuição do número "1", quando a informação estiver presente, e "0", quando ela não for constatada. Logo, esperase que sejam apresentados 8 pontos sobre "Itens previstos na Resolução CNE/CP n. ${ }^{\circ}$ 2/2012; 6 pontos a respeito de "A instituição promove ações orientadas pelos princípios da EA"; 9 pontos a cerca de "A instituição promove ações orientadas pelos objetivos da EA"; 40 pontos relativos à "A instituição contempla"; 4 pontos relativos à "A organização curricular contempla"; e 89 pontos com relação ao "O planejamento curricular e de gestão da instituição".

\section{DESCRIÇÃO E ANÁLISE DOS DADOS}

Com a coleta finalizada, coube analisar como a Educação Ambiental é abordada no curso de graduação em Ciências Contábeis, da UFERSA, e pela própria instituição. Por conseguinte, analisou-se o que está previsto no PPI, PGLS e PDI, quanto à EA, como ilustrado na Tabela 1. Quando se trata do PPI, Francisco et al. (2013) comentam que esse é um instrumento que contempla o planejamento estratégico da instituição, uma vez que aborda aspectos filosóficos, teóricos, metodológicos e de responsabilidade social, como os que preconiza a EA. 
Tabela 1 - Previsão de aplicação da EA nos documentos institucionais da UFERSA

\begin{tabular}{l|c|c|c}
\hline \multicolumn{1}{c|}{ Dimensões } & PPI & PGLS & PDI \\
\hline${\text { Itens previstos na Resolução CNE/CP n. }{ }^{0} \text { 2/2012 }}^{\prime}$ & 0,125 & - & 0,375 \\
A instituição promove ações orientadas pelos Princípios da EA & 0,167 & - & - \\
A instituição promove ações orientadas pelos Objetivos da EA & 0,333 & - & - \\
A instituição contempla & - & 0,050 & - \\
A organização curricular contempla & 0,250 & - & 0,250 \\
O planejamento curricular e de gestão da instituição & 0,034 & - & 0,090 \\
\hline
\end{tabular}

Fonte: Dados da pesquisa (2018).

Analisando o PPI da UFERSA, constata-se que existe uma singela preocupação com o desenvolvimento de ações orientadas para os objetivos da EA, como preceitua a Resolução CNE/CP n. ${ }^{\circ}$ /2012. Dentre os itens que apontam para isso, tem-se a ideia de "desenvolver a compreensão integrada do meio ambiente em suas múltiplas e complexas relações para fomentar novas práticas sociais de produção e consumo", bem como "estimular a mobilização social, política e o fortalecimento da consciência crítica sobre a dimensão socioambiental" e "fomentar e fortalecer a integração entre ciência e tecnologia, visando à sustentabilidade socioambiental", por meio da criação de cursos de graduação focados no uso da tecnologia e preocupados com a questão social e humana. Apesar disso, nota-se que instituição ainda carece de ações que abarque todas as dimensões capazes de promover a EA e a sustentabilidade socioambiental da própria instituição e dos indivíduos que a mesma forma.

Em relação ao PGLS, denominado em outras instituições como Programa de Gestão de Resíduos Sólidos (PGIRS) ou Sistemas de Gestão Ambiental (SGA), nota-se que o cuidado com a adoção de políticas voltadas à EA carece de atenção especial. Isso, porque, a IES objeto de análise, embora possua um documento específico para tratar da temática ambiental e relacionar como a instituição deve se comporta diante do ambiente natural, nota-se que a UFERSA só consegue relacionar a dimensão ambiental com ações de trabalho capazes de promover a "redução no consumo de água, energia e material de expediente", o que compromete a adoção da Agenda Ambiental na Administração Pública (A3P) (LUIZ et al., 2013) ou a inclusão de programas de gestão ambiental (VIEIRA; ECHEVERRIA, 2013). No entanto, esse tipo de comportamento pode corroborar com os ideais de produtividade preconizados nos SGA, como destacam Tauchen e Brandli (2006), o que também pode refletir no compromisso das IES com a formação de indivíduos preparados para a atuação profissional e comprometidos com a causa ambiental.

No que concerne às políticas institucionais, que devem estar contidas no PDI, os dados indicam que o corpo gestor da UFERSA delega aos cursos, a promoção da EA e sua previsão no conteúdo do PPC. Logo, percebe-se que foge do ideal da promoção da EA em qualquer tipo de ambiente, ou seja, formal ou informal, como determina a Lei n. ${ }^{\circ}$ 9.795/1999 e a Resolução CNE/CP n. ${ }^{\circ}$ 2/2012. Em se tratando 
do que foi possível observar com a análise do PDI, que de acordo com Francisco et al. (2013) deve contemplar em seu conteúdo o compromisso, missão e valores da instituição, a abordagem de conteúdos voltados à "ética socioambiental" e inclusão da "dimensão socioambiental no eixo de formação profissional", são simplistas, embora sejam essenciais para promover a EA nos indivíduos em formação.

Considerando os pontos enumerados, quanto ao PPI e PDI, Munaretto e Busanello (2014) comentam que muitas vezes esses documentos estão desarticulados e suas ações sequer são abordadas entre as metas formativas previstas no PPC dos cursos de graduação. Já em relação ao PGLS, similar ao SGA abordado por Tauchen e Brandli (2006), compreende-se que a apresentação desse instrumento é essencial para o estabelecimento de uma cultura sustentável e pautada na preservação do ambiente natural. Assim sendo, constata-se que a desarticulação entre esses documentos é algo comum, apesar de refletir os desafios que as IES precisam se atentar para promover a EA e a longevidade da instituição (WACHHOLZ, 2017).

Em se tratando dos grupos de pesquisa cadastrados pelos docentes da UFERSA, constata-se que a preocupação com a questão ambiental é pertinente, o que reforça a ideia da multidisciplinaridade apontada por Galvão e Tenório (2009). Isso, porque, dentre as áreas que abarcam essa temática de forma predominante, na UFERSA, destacam-se a da Administração, Arquitetura e urbanismo, Ciências ambientais, Ecologia, Engenharia agrícola, Engenharia civil, Engenharia de materiais e metalúrgica, Engenharia sanitária, Geociências e Química. Isso mostra que o corpo docente se interessa pela temática ambiental e considera em sua análise a especificidade da área em que atuam, apesar de apenas um grupo certificado, para tratar de forma específica sobre a EA, denominada de "Programa de EA para todos".

Ante ao exposto, destaca-se que a multidisciplinaridade dos grupos de pesquisa preocupados com a causa ambiental também se reflete nos projetos de pesquisa, extensão e ensino da instituição, como ilustrado na Tabela 2, apesar de não receber um tratamento específico para a área Contábil. Logo, percebe-se que o tripé da universidade tem certo compromisso com o ambiente natural e a formação de indivíduos que tenham o mínimo de conhecimento sobre a EA, o que lhes permite desenvolver uma consciência crítica sobre as relações da sociedade com as questões ambientais, como determina a Lei . $^{\circ}$ 9.795/1999 e a Resolução CNE/CP n. ${ }^{\circ}$ 2/2012. Nesse contexto, quando se destaca os projetos de pesquisa sobre EA, constata-se que há dois vigentes e cadastrados internamente, denominados de "Educação ambiental nos cursos de Administração do Nordeste brasileiro" e "O discurso de educação ambiental em práticas de leitura de professoras do/no campo: identidade de gênero e letramentos múltiplos". 
Tabela 2 - Previsão de adoção da EA em projetos institucionais da UFERSA

\begin{tabular}{l|c|c|c}
\hline \multicolumn{1}{c|}{ Dimensões } & Pesquisa & Extensão & PPC \\
\hline Itens previstos na Resolução CNE/CP n. ${ }^{\circ}$ 2/2012 & 0,375 & 0,125 & 0,500 \\
A instituição promove ações orientadas pelos Princípios da EA & - & 0,667 & 0,667 \\
A instituição promove ações orientadas pelos Objetivos da EA & 0,556 & 0,222 & 0,667 \\
A instituição contempla & - & 0,125 & - \\
A organização curricular contempla & - & - & 0,250 \\
O planejamento curricular e de gestão da instituição & - & 0,045 & - \\
\hline
\end{tabular}

Fonte: Dados da pesquisa (2018).

Quando se destaca os projetos de pesquisa vigentes, que abarcam a EA destacase que embora observem o viés da educação, os mesmos possuem propostas distintas. Isso, porque, um foca na formação auferida no Ensino Superior, ao passo em que o outro avalia as práticas docentes dos indivíduos que atuam no processo de letramento, o que condiz com a demanda a Lei n. ${ }^{\circ}$ 9.795/1999 e da Resolução CNE/ $\mathrm{CP} n .^{\circ} 2 / 2012$, quanto ao desenvolvimento da temática em todos os níveis formativos. Isso corrobora com as discussões levantadas por Gonçalves-Dias et al. (2009), quanto à inserção da EA no processo formativo dos indivíduos, ao passo em que se reflete na sua conduta e relação como meio ambiente, como apontam Brandalise et al. (2014).

Em relação aos projetos de extensão, os dados indicam que o corpo docente da UFERSA se preocupa com o desenvolvimento de ações capazes de alinhar as discussões pertinentes à $E A$, às demandas da sociedade. Isso mostra certo cuidado com a promoção de ações orientadas tanto para os princípios de "formação, análises, estudos e produção de conhecimento sobre o meio ambiente", como do "pluralismo de ideias e concepções pedagógicas", "vinculação entre ética, educação, trabalho e práticas sociais na garantia da continuidade dos estudos e qualidade social da educação" e " articulação na abordagem de uma perspectiva crítica e transformadora dos desafios ambientais a serem enfrentados pelas atuais e futuras gerações, nas dimensões locais, regionais, nacionais e globais". Tudo isso, mediante o desenvolvimento de práticas apropriadas para a sobrevivência da humanidade (DIAS, 2004) e o fomento da sustentabilidade (ROOS; BECKER, 2012).

Ademais, quando se observa os objetivos da EA, nota-se que os projetos de extensão tendem a "desenvolver a compreensão integrada do meio ambiente em suas múltiplas e complexas relações, para fomentar novas práticas sociais e de produção e consumo", como sinaliza Tauchen e Brandli (2006) e Brandalise et al. (2014). Além de "incentivar a participação individual e coletiva, permanente e responsável, na preservação do equilíbrio do meio ambiente, entendendo-se a defesa da qualidade ambiental como um valor inseparável do exercício da cidadania", como sugere e é observado por Santos (2007). Com isso, nota-se que apesar de não abarcar todos os pontos concernentes à Lei n. ${ }^{\circ} 9.795 / 1999$ e da Resolução CNE/CP n. ${ }^{\circ}$ 2/2012, a preocupação com as relações do indivíduo com o ambiente natural é clara e pode 
interferir tanto na formação dos discentes, como em sua atuação profissional.

No que concerne ao PPC, que reflete a proposta formativa dos cursos de graduação (TEIXEIRA; TEIXEIRA, 2006), nota-se pelo projeto vigente que alguns dos princípios e objetivos da EA estão previstos de forma abrangente, inclusive destacando em sua organização curricular a questão da "inserção dos conhecimentos concernentes a EA como conteúdo dos componentes já constantes no currículo". Logo, alinha-se ao ideal formativo previsto como perfil desejado aos egressos dos cursos de Ciências contábeis, ou seja, que o capacite a atender uma heterogeneidade de demandas sociais (ONU, 1998), bem como solucionar situações-problemas (MEC, 2004) e atender às demandas locais (FBC, 2017). Isso corrobora com a lógica formativa constatada por Ribeiro, Nascimento e Bellen (2010), ao avaliar a percepção dos coordenadores de curso da área Contábil, quanto à inserção da temática ambiental, com vias a promover o uso eficiente dos recursos e a sustentabilidade.

Quanto ao PPC, Palma, Alves e Silva (2013) destacam que poucos cursos abordam a questão da EA nesse tipo de documento, quando não há uma disciplina específica para tratar da temática. Nesse sentido, Munaretto e Busanello (2014) comentam que a inserção da EA costuma ocorrer formalmente, ao se considerar a destinação de uma carga-horária específica para tratar da temática, seja mediante disciplina obrigatória ou optativa, apesar de muitas vezes assumir uma postura mais transversal. Diante disso, nota-se que quando a EA não assume um caráter formal, por meio de disciplinas, delega-se à temática uma questão mais transversal e que depende do perfil do docente e da sua sensibilidade ao assunto.

Compreendendo que nem todos os conteúdos desenvolvidos em sala ficam claramente expressos no PPC dos cursos de graduação, procedeu-se com a análise dos programas dos componentes ou disciplinas previstas no PPC e ajustados na matriz curricular do curso, como disposto na Tabela 3. Os dados indicam que apenas uma disciplina do eixo de formação profissional abarca a temática da EA (Contabilidade ambiental e responsabilidade social), mesmo que de forma singela, ao relacionar o meio ambiente com ações voltadas a EpS. Para Calixto (2006) e Galvão e Tenório (2009), essa disciplina é essencial para o processo formativo dos discentes, mas nem sempre promove a multidisciplinaridade requerida pela $E A$, uma vez que seus objetivos estão mais vinculados ao ideal da EpS. Segundo a UNESCO (2017), a EpS foca na sustentabilidade ambiental, social e econômica, uma vez que prepara o indivíduo para a gestão sustentável das organizações. 
Tabela 3 - Abordagem da EA por conteúdo de formação*

\begin{tabular}{|c|c|c|c|c|c|}
\hline Dimensões & $\mathrm{B}$ & $P$ & TP & $E Q$ & C \\
\hline Itens previstos na Resolução CNE/CP n. ${ }^{\circ}$ 2/2012 & & 1 & & & \\
\hline A instituição promove ações orientadas pelos Princípi & & & & & \\
\hline A instituição promove ações orientadas pelos Objetiv & & & & & \\
\hline A instituição contempla & & & & & 1 \\
\hline A organização curricular contempla & & 1 & & & 2 \\
\hline O planejamento curricular e de gestão da instituição & & & & & 3 \\
\hline
\end{tabular}

*Nota: B - Formação básica; P - Formação prática; TP - Formação teórico-prática; EQ - Formação em estudos quantitativos; C - Formação complementar.

Fonte: Dados da pesquisa (2018).

No que concerne aos componentes curriculares de Formação básica, constatase que das 9 (nove) disciplinas inclusas nesse eixo formativo, 8 (oito) dispunham do conteúdo programático para análise e que dentre as mesmas não há qualquer previsão quanto ao estudo da EA. Isso mostra que o curso objeto de análise não tem preocupação com a inserção de conteúdos correlatos à $E A$, no que tange às disciplinas transversais e que são compartilhadas em outras áreas formativas. Nesse contexto, considerando o que está previsto na Resolução CNE/CP n. ${ }^{\circ} 2 / 2012$, esperava-se que o tema da EA fosse abordado na disciplina de "Ética e legislação profissional", uma vez que a inserção de discussões sobre "ética socioambiental" pode maximizar a atuação do profissional, ao passo em que permite construir um ambiente ecologicamente mais equilibrado (KOPEGINSKI; SAKAMOTO, 2010).

Já quanto aos componentes pertinentes à Formação profissional, os dados indicam que das 22 (vinte e duas) disciplinas inclusas nesse eixo formativo, que o conteúdo programático está disponível e que apenas o componente de "Contabilidade ambiental e responsabilidade social" prevê algo relacionado ao que preceitua a Resolução CNE/CP n. ${ }^{\circ}$ 2/2012. Logo, compreende-se que apesar da temática ambiental ser considerada importante para a formação do indivíduo, nem sempre seus ideais são prioritários ou repassados mediante disciplinas formais, por questões estruturais, culturais e sociais (CALIXTO 2006). Nesse contexto, nota-se que a disciplina mencionada destaca a EA como "uma prática educativa integrada", que se fundamenta na "transversalidade, mediante temas com a sustentabilidade socioambiental", como se é de esperar dos cursos que interferem na formação de indivíduos que irão atuar no ambiente de negócio (GONÇALVES-DIAS et al., 2009).

Fazendo uma analogia entre as disciplinas da Formação teórico-prática (3) e Formação em estudos quantitativos (3), contata-se que todos os componentes objeto de estudo detinham seu conteúdo programático disponível para análise. Nesse sentido, considerando que abarcam componentes inerentes a prática Contábil exigida pelo campo de atuação profissional do Contador, bem como Modelos matemáticos e estatísticos, já se esperava que seu conteúdo programático não contemplasse nada a respeito da EA. Isso, porque, se configuram como disciplinas de caráter mais técnico e 
que deixam pouco ou nenhum espaço para análises teóricas mais robustas. Segundo Calixto (2006), tal fato se justifica em função das dificuldades estruturais, culturais e sociais da instituição que oferece o curso, como em relação a própria formação do corpo docente.

Em se tratando da Formação complementar, que abarca estudos transversais inerentes à própria formação do Contador, bem como desenvolvidos ou tratados com predileção em cursos diversos ou complementares a sua atuação profissional, identificou-se que há 56 (cinquenta e seis) possibilidades, das quais foi possível analisar o conteúdo programático de 41 (quarenta e um) componentes. Ao identificar o curso que originalmente detém a disciplina em seu eixo formativo e o conteúdo programático das mesmas, constatou-se que os componentes de "Auditoria ambiental e ecologia", "Direito ambiental" e "Gestão ambiental e responsabilidade social" abordam a temática da EA. Apesar disso, pela própria natureza da disciplina em outros cursos, como componente obrigatório ou equivalente a obrigatório, nem sempre os discentes conseguem matrícula quando a turma está aberta, seja em razão do turno, choque de horário ou número de vagas oferecidas e que permitam ao curso que solicitam tais componentes, atender além da sua demanda obrigatória.

Os dados também indicam que embora haja uma concentração de ações relacionadas à EA em componentes curriculares complementares (3), compreendidos como optativos ou equivalentes a optativos, nem sempre os discentes em formação na área Contábil têm acesso a essas disciplinas ou acesso a informações específicas sobre a temática. Isso mostra que a inclusão de ciclos de palestras ou o uso de ferramentas alternativas de transmissão do conhecimento, como a distribuição de cartilhas, visitas orientadas, dentre outras, podem potencializar o desenvolvimento de ações focadas na EA (BARBIERI, 2004). Ademais, pela própria confusão nos conceitos de EA e EpS, compreende-se que o preparado do indivíduo, em formação no ambiente universitário, deve considerar o estabelecimento de uma relação saudável da temática ambiental com a formação requerida para a atuação profissional (TEIXEIRA; TEIXEIRA, 2006; SILVA et al., 2015).

Ao analisar como a EAé abordada no curso de graduação em Ciências Contábeis, da UFERSA, nota-se que há uma desarticulação entre o PPI, PDI, PGLS, PPC e conteúdo previstos nas disciplinas. Isso corrobora com os dados obtidos por Munaretto e Busanello (2014), que destacam não haver um vínculo institucional seguro, capaz de promover a EA, como determina a Lei n. ${ }^{\circ}$ 9.795/1999 e a Resolução CNE/CP n. ${ }^{\circ}$ 2/2012. Logo, como já previsto no estudo de Petarnella, Silveira e Machado (2017), os cursos oferecidos pelas IES devem criar mecanismos ou táticas que efetivem a promoção da EA e tornem suas ações perceptíveis a toda a comunidade acadêmica, como já destacava Pase et al. (2014).

\section{CONSIDERAÇÕES FINAIS}

Com o intuito de analisar como a Educação Ambiental é abordada no curso de graduação em Ciências Contábeis, UFERSA, e pela própria instituição, procedeu-se com a análise documental do PPI, PDI, PGLS, PPC e planos de disciplinas. Tudo 
isso, de modo a reunir dados que permitissem averiguar se o curso e a instituição preveem a adoção do que preceitua a Lei n. ${ }^{\circ}$ 9.795/1999 e a Resolução CNE/CP n. ${ }^{\circ}$ 2/2012, no que tange à EA. Isso, porque, a EA discutida no ambiente universitário deve contemplar a formação de indivíduos que detenham uma consciência crítica a respeito de suas relações com o ambiente natural.

Ante ao exposto, constatou-se que PPI trata a questão da EA sob a perspectiva da sustentabilidade da própria instituição objeto de análise. Complementarmente, o PGLS dispõe sobre as estratégias que podem viabilizar a proteção do ambiente natural e as perspectivas que os indivíduos, que compõem a instituição, devem assumir de modo a permanecerem atentos a manutenção de uma relação saudável e sustentável com o meio ambiente. O PDI, pela própria conjuntura que cobre, aborda questões relacionadas às ações que a UFERSA tem a intenção de promover em favor do meio ambiente e consolidação da EA.

Ao avaliar o PPC do curso de Ciências Contábeis da UFERSA, evidenciou-se quanto à $E A$, que poucas disciplinas abordam o assunto, o que é preocupante quando se deseja viabilizar a construção de um conhecimento, formal ou informal, sobre o que preceitua a Lei n. ${ }^{\circ}$ 9.795/1999 e a Resolução CNE/CP n. ${ }^{\circ}$ 2/2012. Em relação aos projetos de pesquisa, identificou-se que a discussão sobre EA é pertinente, mas nem sempre desenvolvida ou tratada no âmbito da formação dos indivíduos que almejam atuar na área Contábil. Esse tipo de comportamento é semelhante em meio aos projetos de extensão, apesar de tratarem de pontos distintos, que de um lado prima pela cidadania ambiental e do outro aborda o fomento da sustentabilidade organizacional.

Complementarmente, ao analisar o conteúdo programático de cada disciplina ofertada ao curso, notou-se que o tema não é abordado entre os componentes dos eixos de formação básico, teórico-prático e de estudos quantitativos. Isso mostra que quanto mais técnica é a proposta formativa de cada eixo formativo, mais distante se torna das discussões pertinentes à EA. No que tange às disciplinas do eixo profissional e complementar, percebe-se que há uma tímida preocupação com a temática da EA, o que por ora confunde com os preceitos da EpS. Isso, porque, a temática é tratada sob o ponto de vista da sustentabilidade organizacional, em componentes tais como: "Auditoria ambiental e ecologia", "Contabilidade ambiental e responsabilidade social", "Direito ambiental", "Gestão ambiental e responsabilidade social".

Considerando os pontos enumerados, destaca-se que não foi possível avaliar a percepção dos docentes, discentes e coordenadores de curso, quanto à inserção da EA no processo de ensino-aprendizagem. Logo, sugere-se para novos estudos, ampliar a análise dos cursos da área Contábil, observando tanto as demais instituições públicas, como as IES particulares e filantrópicas, de modo a averiguar se existe diferença quanto à discussão da temática, em função das características da instituição, bem como incluir outros cursos que possuem relação direta com o ambiente natural, como objeto de estudo. Cabe ainda, avaliar a efetividade dos projetos ambientais existentes nas IES, em função da Lei n. ${ }^{\circ}$ 9.795/1999 e a Resolução CNE/CP n. ${ }^{\circ}$ 2/2012.

Por fim, compreende-se que embora a discussão seja necessária em todos os ambientes, formais e informais, a EA ainda carece de atenção e cuidado por parte da 
instituição e do curso objeto de análise. Isso, porque, seu principal papel consiste em formar indivíduos preparados não só para a atuação profissional, mas para vivenciar a sustentabilidade em todos os seus aspectos. Os dados também indicam que o cuidado com as normas vigentes se faz necessário, para que os cursos de graduação possam se manter atentos às discussões sobre EA e a efetivá-la em sua plenitude.

\section{REFERÊNCIAS}

BARBIERI, J. C. A educação ambiental e a gestão ambiental em cursos de graduação em administração: objetivos, desafios e propostas. RAP, Rio de Janeiro, v. 38, n. 6, p. 919-946, nov./dez. 2004.

BARBIERI, J. C.; SILVA, D. Desenvolvimento sustentável e educação ambiental: uma trajetória comum com muitos desafios. Revista de Administração Mackenzie, São Paulo, v. 12, n. 3, p. 51-82, maio/jun. 2011.

BARDIN, L. Análise de conteúdo. 3. reimp. Lisboa: Edições 70, 2011.

BEUREN, I. M. et al. Como elaborar trabalhos monográficos em contabilidade: teoria e prática. São Paulo: Atlas, 2013.

BRANDALISE, L. T. et al. O reflexo da disciplina de educação ambiental na percepção e conduta dos universitários. Revista Pretexto, Belo Horizonte, v. 15, n. 4, p. 11-26, out./dez. 2014.

BRASIL. Lei n. 4.320, 17 de março de 1964. Institui Normas Gerais de Direito Financeiro para elaboração e controle dos orçamentos e balanços da União, dos Estados, dos Municípios e do Distrito Federal. Disponível em: http://www.planalto. gov.br/ccivil 03/LEIS/L4320.htm . Acesso em: 17 dez. 2018.

BRASIL. Lei n. ${ }^{\circ}$ 6.404, 15 de dezembro de 1976. Dispõe sobre as Sociedades por Ações. Disponível em: http://www.planalto.gov.br/ccivil 03/LEIS/L6404consol.htm. Acesso em: 17 dez. 2018.

BRASIL. Lei n. 9.795, de 27 de abril de 1999. Dispõe sobre a educação ambiental, institui a Política Nacional de Educação Ambiental e dá outras providências.

Disponível em: http://www2.camara.leg.br/legin/fed/lei/1999/lei-9795-27-abril-1999373224-publicacaooriginal-1-pl.html. Acesso em: 15 ago. 2018.

BRASIL. Resolução CNE/CES n. ${ }^{0}$ 10/2004, 16 de dezembro de 2004. Institui as Diretrizes Curriculares Nacionais para o Curso de Graduação em Ciências Contábeis, bacharelado, e dá outras providências. Disponível em: http://portal.mec. gov.br/cne/arquivos/pdf/rces10 04.pdf. Acesso em: 17 dez. 2018. 
BRASIL. Resolução CNE/CP n. ${ }^{\circ}$ 2, de 15 de junho de 2012. Estabelece as Diretrizes Curriculares Nacionais para a Educação Ambiental. Disponível em: http:// conferenciainfanto.mec.gov.br/images/conteudo/iv-cnijma/diretrizes.pdf. Acesso em: 15 ago. 2018.

BUGARIM, M. C. C.; OLIVEIRA, O. V. A evolução da Contabilidade no Brasil. In: Simpósio de Excelência em Gestão e Tecnologia, 11., 2014, Resende. Anais [...]. Resende: AEDB, 2014.

CALIXTO, L. O ensino da contabilidade ambiental nas universidades brasileiras: um estudo exploratório. Revista Universo Contábil, v. 2, n. 3, p. 65-78, set./dez. 2006.

CARNEIRO, J. D. (Coord.). Matriz curricular para cursos de Ciências Contábeis: uma proposta da Fundação Brasileira de Contabilidade. Brasília: FBC, 2017.

FRANCISCO, T. H. A. et al. A contribuição do PDI nas atividades de planejamento e gestão das instituições de Educação Superior. Revista GUAL, v. 5, n. 3, p. 81-107, dez. 2012.

FRANCISCO, T. H. A. et al. A relação entre o índice geral de cursos e o projeto pedagógico institucional: análise de faculdades isoladas. Revista Alcance, v. 20, n. 2, p. 186-202, abr./jun. 2013.

GALVÃO, C. C. A.; TENÓRIO, J. N. B. Um estudo sobre o ensino da contabilidade ambiental nos cursos de graduação em Ciências contábeis. In: Congresso Brasileiro de Custos, 16., 2009, Fortaleza. Anais [...]. Fortaleza: ABC, 2009.

GIL, A. C. Métodos e técnicas de pesquisa social. 6. Ed. São Paulo: Atlas, 2008.

GONÇALVES-DIAS, S. L. F. et al. Consciência ambiental: um estudo exploratório sobre suas implicações para o ensino de Administração. RAE-eletrônica, v. 8, n. 1, art. 10, jan./jun. 2009.

HERNÁNDEZ-SAMPIERI, R. H.; FERNÁNDEZ-COLLADO, C. F.; LUCIO, P. B. Metodologia da pesquisa. 3. ed. São Paulo: McGraw-Hill, 2006.

JACOBI, P. Educação ambiental, cidadania e sustentabilidade. Cadernos de pesquisa, n. 118, p. 189-205, mar. 2003.

KOPEGINSKI, S. I. R.; SAKAMOTO, B. A. M. Ética e educação ambiental. In: ROESLER, M. R. B. (Org.). Por um meio ambiente ecologicamente equilibrado: pensamentos e diálogos. Cascavel: Edunioeste, 2010. 
LUIZ, L. C. et al. Agenda ambiental na administração pública (A3P) e práticas de sustentabilidade: estudo aplicado em um instituto federal de educação, ciência e tecnologia. Administração Pública e Gestão Social, v. 5, n. 2, p. 54-62, abr./jun. 2013.

MACHADO, V. S. A.; CASA NOVA, A. P. C. Análise comparativa entre os conhecimentos desenvolvidos no curso de graduação em Contabilidade e o perfil do Contador exigido pelo mercado de trabalho: uma pesquisa de campo sobre Educação Contábil. Revista de Educação e Pesquisa em Contabilidade, Brasília, v. 2, n. 1, art. 1, p. 1-23, jan./abr. 2008.

MARTINS, A. O.; SANCHES, R. C. F. Por uma educação para sustentabilidade. Veredas do Direito, Belo Horizonte, v. 9, n. 17, p. 61-78, jan./jun. 2012.

MARTINS, G. A.; THEÓPHILO, C. R. Metodologia da investigação científica para as Ciências Sociais Aplicadas. São Paulo: Atlas, 2007.

MUNARETTO, L. F.; BUSANELLO, S. Um estudo sobre inserção da educação ambiental nos projetos pedagógicos dos cursos do CESNORS/UFSM. Revista de Administração UFSM, Santa Maria, v. 7, Edição especial, p. 24-39, set. 2014.

OTT, E.; PIRES, C. B. Estrutura curricular do curso de Ciências Contábeis no Brasil versus estruturas curriculares propostas por organismos internacionais: uma análise comparativa. Revista Universo Contábil, Blumenau, v. 6, n. 1, p. 28-45, jan./mar. 2010.

PALMA, I. R. Análise da percepção ambiental como instrumento ao planejamento da educação ambiental. 83 fls. 2005. Dissertação (Mestrado em Engenharia) - Universidade Federal do Rio Grande do Sul, Porto Alegre, 2005.

PALMA, L. C.; ALVES, N. B.; SILVA, T. N. Educação para a sustentabilidade: a construção de caminhos no Instituto Federal de Educação, Ciência e Tecnologia do Rio Grande do Sul (IFRS). Revista de Administração Mackenzie, São Paulo, v. 14, n. 3, p. 83-118, maio/jun. 2013.

PASE, J. et al. Educação ambiental na Universidade: percepção dos acadêmicos do curso de Administração em Santa Maria-RS. Revista Capital Científico, Guarapuava, v. 12, n. 2, p. 65-82, abr./jun. 2014.

PELEIAS, I. R. et al. (org.). Didática do ensino da contabilidade: aplicável a outros cursos superiores. São Paulo: Saraiva, 2006. 
PEREIRA, R. S. Educação ambiental na formação do administrador - (José Carlos Barbieri, Dirceu da Silva - 2011). Administração: Ensino e Pesquisa, v. 14, n. 2, p. 403-407, 2013.

PETARNELLA, L.; SILVEIRA, A.; MACHADO, N. S. Educação Ambiental e Ensino de Sustentabilidade: Reflexões no Contexto da Administração. Revista de Gestão Ambiental e Sustentabilidade, v. 6, n. 1, p. 1-12, 2016.

PINHEIRO, L. O. et al. A percepção dos discentes do curso de graduação em Ciências Contábeis da UFERSA quanto à adoção de novas ferramentas de ensinoaprendizagem. In: Congresso UFERSA de Contabilidade, 2., 2015, Mossoró. Anais [...]. UFERSA: Mossoró, 2015.

RIBEIRO, A M.; NASCIMENTO, L. F.; BELLEN, H. M. V. A relevância da temática ambiental na formação dos bacharéis em Ciências contábeis: a percepção dos coordenadores de curso. SINERGIA, Rio Grande, v. 14, n. 1, p. 35-45, 2010.

ROOS, A.; BECKER, E. L. S. Educação ambiental e sustentabilidade. Revista eletrônica em gestão, educação e tecnologia ambiental, v. 5, n. 5, p. 857-866, 2012.

SANTOS, A. M. D. Educação Ambiental: matéria relevante para as Ciências da Administração nas dimensões acadêmica e organizacional. Revista de Ciências da Administração, v. 9, n. 17, p. 132-149, 2007.

SCHMIDT, P.; SANTOS, J. L. História do pensamento contábil. São Paulo: Atlas, 2000 (Coleção resumos de Contabilidade).

SILVA, A. M. et al. Comportamentos ambientalmente responsáveis e sua relação com a educação ambiental. Revista de Gestão Ambiental e Sustentabilidade, v. 4, n. 1, p. 1-16, 2014.

SILVA, E. C. O.; RÊGO, T. F. Proposta formativa versus desempenho: um estudo comparativo entre os cursos de graduação em Ciências Contábeis das IFES brasileiras. Revista Ambiente Contábil, Natal, v. 6, n. 2, p. 55-74, jul./dez. 2014.

SILVA, V. R.; MIRANDA, G. J.; PEREIRA, J. M. ENADE e Proposta curricular do CFC: um estudo em cursos brasileiras de Ciências Contábeis. Revista de Educação e Pesquisa em Contabilidade, Brasília, v. 11, n. 3, p. 261-275, jul./set. 2017. 
SOUZA, L. F. R.; RÊGO, T. F.; GIESTA-CABRAL, L. C. Educação Ambiental e Educação para a Sustentabilidade: um Estudo Bibliométrico das Produções Científicas do EnANPAD, ENGEMA e ECOINOVAR. In: Encontro da ANPAD, 41., 2017, São Paulo. Anais [...]. São Paulo: ANPAD, 2017.

TAUCHEN, J.; BRANDLI, L. L. A gestão ambiental em instituições de ensino superior: modelo para implantação em campus universitário. Gestão \& Produção, v. 13, n. 3, p. 503-515, set./dez. 2006.

TEIXEIRA, A. C. E. A.; TEIXEIRA, H. A. O ensino de administração e a educação ambiental: algumas reflexões sobre os currículos e a importância da formação de agentes multiplicadores nas organizações. Revista Gestão e Planejamento, Salvador, ano 7, v. 13, jan./jun. 2006.

UNESCO. Education for Sustainable Development Goals: Learning Objectives. 2017. Disponível em: http://unesdoc.unesco.org/images/0024/002474/247444e.pdf. Acesso em: 06 ago. 2017.

VIEIRA, J. E.; ECHEVERRÍA, A. R. A administração pública e a educação ambiental no Programa de Gestão Integrada de Resíduos Sólidos: uma reflexão de uma experiência local. Cadernos EBAPE.BR, v. 5, n. 1, p. 1-15, 2013.

WACHHOLZ, C. B. Campus sustentável e educação: desafios ambientais para a universidade. 181 fls. 2017. Tese (Doutorado em Educação) - Pontifícia Universidade Católica do Rio Grande do Sul, Porto Alegre, 2017.

YIN, R. K. Estudo de caso: planejamento e métodos. Bookman: Portalegre, 2015.

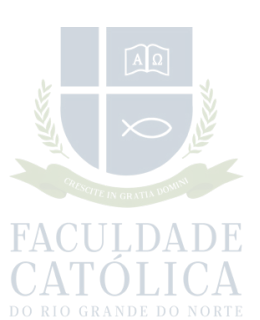

